In the subsequent discussion on the two papers, many helpful remarks were made upon the provision of reading apparatus by the adaptation of available mechanisms, such as cinema projectors, to the purpose, and there is no doubt that those individuals who possess the skill and equipment to carry out the minor constructional modifications needed can produce a reasonably efficient machine for enlarging the films, certainly for the purposes of individual research. But one has only to handle an efficient commercial reader, specially designed for the work, to realize that its construction is the result of long experience of the problem, and the results are very satisfying. A small exhibition of reading apparatus, arranged by the Aslib Microfilm Service, proved very popular and instructive.

The final session of the Conference, under the chairmanship of Mr. T. R. Dawson, of the Research Association of British Rubber Manufacturers, was devoted to a paper by Mr. J. E. Wright of the Post Office Research Station on "Some Methods used in the Special Library of a Research Department", followed by one on "War-time Books and Periodicals": some Suggestions", by Mr. B. M. Headicar. Mr. Wright's paper was not merely an account of the methodology of the particular library of the Post Office Research Station, but also contained a rich fund of information and suggestions adapted to use by any similar library; a series of clues to specific requests for information was perhaps the most interesting and instructive section of the paper. Mr. Headicar dealt in his customary adept manner with a multiplicity of practical details, including suggestions for economy in paper and binding; he illustrated his address by greatly appreciated practical demonstrations of the methods recommended.

\section{SEASONING OF TIMBER}

\section{BY ALEXANDER L. HOWARD}

Necessitas non habet legem ("Piers Plowman", 1377).

W HILE it is true that the harsh dictates of necessity have resulted in many discoveries and useful practices in the seasoning of timber, laws regarding the process are adamant; and although simple, the principles which govern the procedure are unalterable. The sap and moisture contents must be drawn out of the wood and the necessary methods employed to bring the wood to that degree of moisture content desired. The process must be varied according to the species of timber and the purpose for which it is required.

Never in the history of Great Britain has this question been of such vital importance as it is to-day. Commodities of all sorts-food, delicate instruments, ammunition, and war material of all kinds-must be packed safely for transport over great distances and under trying conditions, and it is essential that the cases used for this purpose can be relied upon to preserve their valuable contents.

Of those materials which can be used, timber plays the most important part. We are forced to rely to a very great extent upon available native timber, which could be put to better use if adequate facilities for seasoning existed.

It has been proved that timber of many kinds, and in the dimensions required, can be seasoned in a satisfactory manner in a short time, and indeed there are already many established kilns fully occupied and successfully working, but in no sense sufficient for the demands of total war. Even though it involves great expense and effort, many more drying kilns of efficient design should be established as quickly as possible to make good this deficiency.

Fortunately, the lessons of the War of 1914-18 and scientific research have enabled us to overcome all the main difficulties, and the chief problem that concerns us is no longer the method to be employed, but the establishment of sufficient kilns throughout the country.

The primary object is to create within the kiln a continuous and regular current of air (at first charged with moisture) to suit the condition of the unseasoned or fractious wood, and then to withdraw the moisture and introduce the heat by carefully controlled degrees, until the desired percentage of moisture contents has been acquired. To accomplish this, it is essential that every square inch of the timber should be sub. jected to an equal volume of the current, and while the dimensions of the kiln play an important part, by far the greater importance lies in the scientific application of the correct combination of moisture and heat.

During the course of the last hundred years, innumerable processes have been tried out, many of which have been patented but later abandoned. Among these systems is a process which might be described as a 'bakery' - that is, one in which the timber is placed in a compartment somewhat similar to an oven. Other ingenious systems have been tried, in which the wood is subjected to a vacuum, with water and steam introduced later. Another process has been to place the timber in boiling water accompanied by the introduction of saccharine or other ingredient, and a still further attempt has been made by the use of an electric current. Most of these, or perhaps all, have been abandoned, at least so far as commercial practice is concerned: at another time, and in more easy circumstances, it would be desirable to enter into further scientific research, which might give us more information and thus secure even better results. At present our endeavour should be to concentrate our attention towards providing that which we know can secure an immediate as well as a satisfactory result.

'Two methods are available, which are what are known as the 'progressive' and the 'compartment' kilns, both well understood and universally accepted.

For large quantities of box boards the progressive method would probably be efficient, but this system would not succeed when applied to the more fractious and difficult woods, when the compartment system should be adopted.

In the progressive kiln the wood is placed on trucks, allowing sufficient air space between the boards. The trucks are moved under control through successive chambers which have been prepared with the necessary saturation of moisture and the introduction of dry heat. The moisture contents are gradually withdrawn and the dry heat increased. On completion, the charge is found to contain that correct percentage of moisture contents which was calculated as ordered.

In the compartment system, as the name implies, the timber is piled with similar air ventilation, but in a fixed chamber where moisture and heat are introduced. As in the case of the progressive kiln, the moisture is gradually withdrawn and the heat 
increased, so that after the necessary period, which varies according to the description and thickness of wood, whether fractious or kindly, the chamber may be opened and the charge will be found to conform to any given degree of moisture contents stipulated. Complete reliance can be placed on either of these methods.

The outlay required to provide an adequate number of such kilns throughout Great Britain will, of course, be heavy, but having regard to the urgency, this consideration ought to be of secondary importance.

An ample supply of properly seasoned timber for the boxing and safe transport of the vital necessities of war is essential to our war effort, and until this question has been adequately dealt with we may suffer serious losses, not only financial but also endangering the health and welfare of our troops and those of our Allies.

\section{NEW AND LITTLE-KNOWN FISHES}

$\mathrm{T}$ THE Stanford Ichthyological Bulletin, published by the Natural History Museum of Stanford University, is responsible for many valuable descriptions of fishes, and the two numbers before us (2, No. 4, Aug. 24, No. 5, Aug. 31, 1942) contain various papers, the most striking of which are George G. Myers's "Studies of South American Freshwater Fishes" and Albert W. C. T. Herre's "New and Little Known Phallostethids, with Keys to the Genera and Philippine Species". The Natural History Museum of Stanford University has amassed a large collection of South American fishes, which, together with the very extensive South American material in the California Academy of Science, forms probably the finest series available anywhere for the study of South American fluviatile ichthyology.

In the present work are included fishes from Amazonian Peru, from Venezuela and from Rio de Janeiro. Especially interesting is Hoplomyzon atrizona n.g. et sp., a new Bunocephalid from Peru, which is armed with a series of bony plates along the body, and apparently has no close relatives. It is adapted for life in swift water and the head has maxillary barbels strongly resembling some of the hill-stream Nematognaths.

Many new Cyprinodonts were collected by Lieut.Col. and Mrs. White in the coastal plain of the State of Rio de Janeiro, their object being to study them in their own aquaria. Fishes of the genus Cynolebias are favourites with aquarists and are known to be annual fishes with a full life-cycle within one year. They are usually found in isolated water holes, swamps and ponds which dry up in the dry season, only the eggs surviving in the mud. After hatching in the wet season, development of the fry is rapid and in some instances full growth is attained in two or three months. The species of this genus, owing to their specialized habitat and seasonal occurrence, are seldom seen by ordinary ichthyologists and are usually only obtained through commercial aquarium fish collectors. The present series is therefore specially valuable. It includes many new forms of these very beautiful small fishes which in life are brilliantly coloured. Five of the new species are described and notes given from colour sketches made from the living material.

Herre's paper on the Phallostethids describes many of these peculiar fishes, which are all very small and almost transparent with very little colouring. The sexes are strongly dimorphic, the male possessing a special bony organ lying on the outside of the head which serves for clasping the female. Eighteen species are so far known, occurring in brackish and salt water in Malaya, Singapore, Siam, Borneo and the Philippines, in mountain brooks in Luzon and lowland freshwater creeks in Siam and Luzon, and in freshwater lakes from the Philippines and off Sumatra. It is expected that many more are yet to be discovered.

\section{SCOTTISH LAKE DWELLINGS*}

$\mathrm{F}$

OR the first time one of the very numerous artificial islands on the Scottish lochs has been examined with a technical skill comparable to that so profitably expended on the crannogs of Somerset and more recently of Ireland. Fortunately, the engineers in charge of the Lochaber Water Power Scheme appreciated the scientific importance of the crannog in the north end of Loch Treig that the scheme had exposed and would destroy. Still more fortunately Prof. Ritchie, then at the University of Aberdeen, was able to take advantage of the opportunity for a thorough investigation of the island's structure.

The crannog proved to differ both in plan and construction from the Glastonbury lake village and the individual laeustrine habitations explored by Munro in Galloway last century and more recently by Hencken in Ireland. While the latter are round, it was rectangular. The basal structure was a framework of squared beams, $65 \mathrm{ft}$. by $42 \mathrm{ft}$., founded upon a bed of large stones that had been laid on a natural elevation in the loch floor. Above this, layers of timbers and of earth and stones, each separated by layers of brushwood, birch-branches or heather, and in all nearly $6 \mathrm{ft}$. thick, supported an upper framework of undressed trunks $57 \mathrm{ft}$. Iong by $30 \mathrm{ft}$. broad. It supported yet another layer of brushwood, above which came the actual dwelling floors, frequently renewed until the total deposit above the upper platform was $3 \mathrm{ft}$. thick. The timber frameworks were kept in place by a double row of upright piles that the excavator shows cannot have served as a defensive palisade.

Access to the island was not provided by any causeway, but a landing stage was found from which a sloping ladder led up to the island's surface. The report emphasizes the structural importance of the brushwork layers both in distributing the weight of superstructures and in cementing together heterogeneous layers.

Ritchie argues convincingly that the usual accounts of the construction of such islands simply will not work with the Treig crannog, and concludes that its builders must have temporarily lowered the waterlevel at this end of the loch. Relics were disappointingly scarce. They confirm literary testimony to the occupation of the island in the sixteenth and seventeenth centuries, but nothing unambiguously distinctive of an earlier period was found, though a leather shoe seems to be derived from a RomanoBritish pattern, and the peculiar technique exemplified in a woollen fabric finds its nearest (but still not exact) parallel in textiles of the Viking Age.

* "The Lake-dwelling or Crannog in Eadarloch, Loch Treig: its Antiquaries Scot., 76, 8-78, with plates IV-XIX and 22 text-figures. 